\title{
Reorganization of effective network structure with dynamic synapses in cortical circuit and its possible functions
}

Yuichi Katori ${ }^{1,2 *}$, Kazuhiro Sakamoto ${ }^{3}$, Hajime Mushiake ${ }^{4}$, Kazuyuki Aihara ${ }^{2}$

From Twenty Second Annual Computational Neuroscience Meeting: CNS*2013

Paris, France. 13-18 July 2013

Synaptic transmission efficacy transiently changes in a short period of time with generation of presynaptic spikes. Depending on changes in releasable neurotransmitters and calcium concentration in presynaptic terminals, the transmission efficacy of the dynamic synapses decreases (short-term depression) or increases (shortterm facilitation) [1]. Dynamical properties of the neural network with dynamic synapses have been intensively investigated [1-3]. In the associative memory network with dynamic synapses, the network exhibits not only

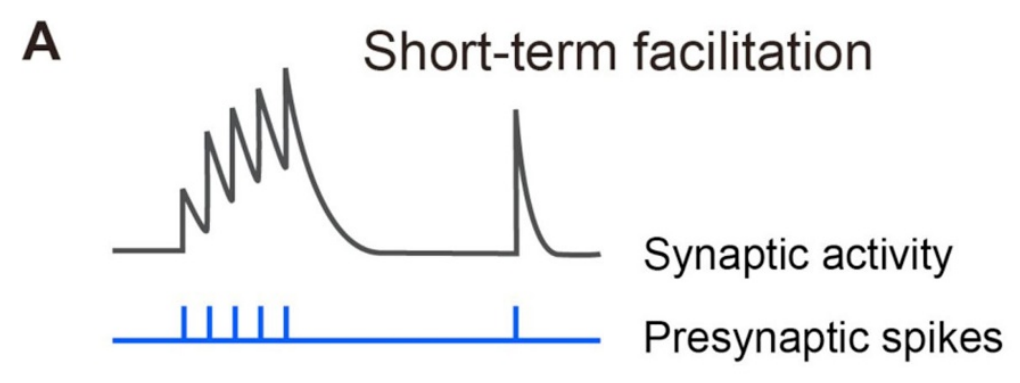

B

Sub-network A
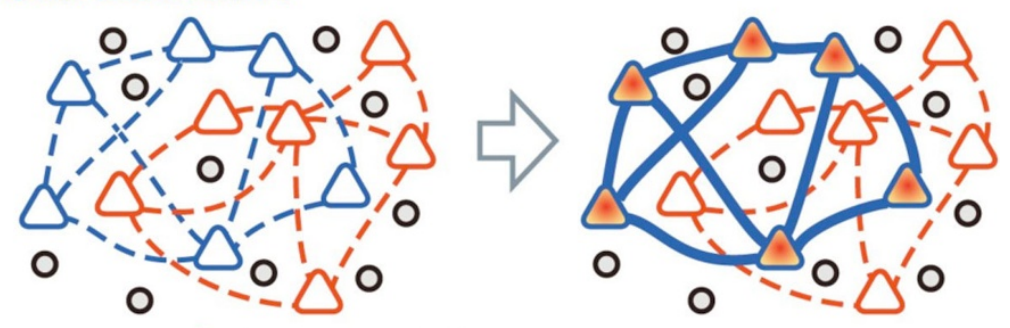

\section{Sub-network B}

Figure 1 Reorganizing network structure with dynamic synapses. A. Schematic time course of synaptic activity with short-term facilitation. B. Depending on the activity of the network, the effective network structure changes transiently.

\footnotetext{
${ }^{1}$ FIRST, Aihara Innovative Mathematical Modelling Project, JST, Institute of Industrial Science, The University of Tokyo, 4-6-1-Cw601 Komaba, Meguro-ku, Tokyo 153-8505, Japan

Full list of author information is available at the end of the article
} 
memory retrieved state but also state transitions among stored memory patterns [2]. Further, we propose that the changes in the synaptic transmission efficacy cause the reorganization of effective network structure and, thereby functions of the network changes dynamically according to a required task [3].

We investigate the properties of the network dynamics with the leaky integrate-and-fire based spiking neural network and the corresponding mean field model. Changes in the synaptic transmission efficacy can be modeled with variables that represent the releasable neurotransmitter and the utilization parameter reflecting the calcium concentration. In the case of the facilitation synapses, the transmission efficacy increases with the successive generation of presynaptic spikes as shown in Figure 1A. Activation of a sub-network facilitates the synaptic connections between the neurons in the sub-network (Figure 1B). We drive the mean field model that captures its population dynamics. Changes in the synaptic efficacy are relatively slow, and the slow variables can be regarded as bifurcation parameters that have influences on the fast variables of the neural activity. On the basis of this concept, we analyze bifurcation structure of the mean field model.

\section{Conclusion}

In the neural network with dynamic synapses, the effective network structure can be reorganized; this causes qualitative changes in the population dynamics (bifurcation). In the presentation, we discuss possible network functions on the basis of this mechanism e.g., generation of sequential actions.

\section{Acknowledgements}

This research was supported by the Aihara Project, the FIRST program from JSPS.

\section{Author details}

${ }^{1}$ FIRST, Aihara Innovative Mathematical Modelling Project, JST, Institute of Industrial Science, The University of Tokyo, 4-6-1-Cw601 Komaba, Meguro-ku, Tokyo 153-8505, Japan. ${ }^{2}$ Institute of Industrial Science, The University of Tokyo, Japan. ${ }^{3}$ Research Institute of Electrical Communication, Tohoku University, 2-1-1 Katahira, Aoba-ku, Sendai 980-8577, Japan. ${ }^{4}$ Department of Physiology, Tohoku University School of Medicine, 2-1 Seiryo-machi Aoba-Ku, Sendai 980-8575 Japan.

Published: 8 July 2013

\section{References}

1. Tsodyks M, Pawelzik K, Markram H: Neural networks with dynamic synapses. Neural Computation 1998, 10(4):821-835

2. Katori $Y$, Otsubo $Y$, Okada M, Aihara K: Stability analysis of associative memory network composed of stochastic neurons and dynamic synapses. Frontiers in Computational Neuroscience 2013, 7:6.

3. Katori Y, Sakamoto K, Saito N, Tanji J, Mushiake H, Aihara K: Representational Switching by Dynamical Reorganization of Attractor Structure in a Network Model of the Prefrontal Cortex. PLOS Computational Biology 2011, 7(11):e1002266.
doi:10.1186/1471-2202-14-S1-P4

Cite this article as: Katori et al:: Reorganization of effective network structure with dynamic synapses in cortical circuit and its possible functions. BMC Neuroscience 2013 14(Suppl 1):P4.

\section{Submit your next manuscript to BioMed Central and take full advantage of:}

- Convenient online submission

- Thorough peer review

- No space constraints or color figure charges

- Immediate publication on acceptance

- Inclusion in PubMed, CAS, Scopus and Google Scholar

- Research which is freely available for redistribution

Submit your manuscript at www.biomedcentral.com/submit
C Biomed Central 